\title{
EFEITO DOS PARÂMETROS OPERACIONAIS DO PROCESSO DE ELETROPOLIMENTO SOBRE A MORFOLOGIA E COMPOSIÇÃO DA SUPERFÍCIE DE NITINOL ${ }^{1}$
}

\author{
Luciane Taís Führ \\ Alana Rocha Schmidt Witt ${ }^{3}$ \\ Leonardo Marasca Antonini ${ }^{4}$ \\ Tiago Schmidt Souza ${ }^{5}$ \\ Denis Villarinho ${ }^{6}$ \\ Célia de Fraga Malfatti ${ }^{7}$
}

\section{Resumo}

A liga de Nitinol tem se destacado para aplicação como biomaterial metálico, devido a sua propriedade de superelasticidade e memória de forma. Contudo, a migração de níquel da liga para o meio onde ela está inserida pode causar prejuízos ao organismo, dado o potencial tóxico desse metal. Diversos processos vêm sendo empregados para minimizar a migração de níquel e para acelerar o processo de osseointegração. O processo de eletropolimento tem sido utilizado, principalmente, para modificar a textura da superfície metálica e favorecer o crescimento celular, acelerando dessa forma o processo de osseointegração. O presente estudo propõe a investigação do efeito dos parâmetros operacionais do eletropolimento com solução ácida sobre a topografia da superfície do Nitinol, A morfologia das amostras eletropolidas foi avaliada por microscopia de força atômica. A composição das superfícies eletropolidas foi avaliada pela técnica de Rutherford BackscatteringSpectroscopy(RBS). Os resultados obtidos mostram que o eletropolimento com ácido fluorídrico tende a formar nanoestruturas, refinando a topografia superficial.Contudo esse tratamento não elimina o níquel na superfície do nitinol.

Palavras-chave: Nitinol; Eletropolimento; Nanoestruturas; Biomaterial.

\section{EFFECT OF ELECTROPOLISHING PARAMETERS ON MORPHOLOGY AND COMPOSITION OF NITINOL SURFACE}

\begin{abstract}
Nitinol alloy is frequently used as a biomaterial metal, for its property of superelasticity and shape memory. However, the nickel release alloy for the body can cause damage by toxic potential of metal. Several processes are been employed to minimize nickel release and to accelerate the osseointegrationprocess. Electropolishing has been used to modify the metallic surface and promote cell growth. The present study aims to investigate the effect of process parameters of the electropolishing with an acid solution on the surface topography of Nitinol. The morphology of electropolished samples was evaluated by atomic force microscopyand the composition of electropolished surfaces was determined byRutherford Backscattering Spectroscopy (RBS). The results show that the electropolishing with hydrofluoric acid tends to form nanostructures, improving the surface topography. However, the layer formed does not eliminate the nickel on the nitinol surface.
\end{abstract}

Keywords:Nitinol; Electropolishing; Nanostructures; Biomaterial.

1 Contribuição técnica ao $68^{\circ}$ Congresso Anual da ABM - Internacional, 30 de julho a 2 de agosto de 2013, Belo Horizonte, MG, Brasil.

2 Eng. Industrial Mecânica, Msc., Doutoranda. Laboratório de Pesquisa em Corrosão (Lapec), Departamento de Engenharia, Universidade Federal do Rio Grande do Sul (UFRGS), RS, Brasil; luciane.fuhr@gmail.com.

3 Biomédica. Mestranda. Lapec, Departamento de Engenharia, UFRGS, RS, Brasil; alanawitt@gmail.com.

4 Químico Industrial, Msc., Doutorando Lapec, Departamento de Engenharia; UFRGS, RS, Brasil;: leomantonini@gmail.com.

5 Graduando em Engenharia Metalúrgica. Lapec, Depto. Engenharia, UFRGS, RS, Brasil; tss_tiago@hotmail.com.

6 Engenheiro mecânico, Msc., Doutorando. Laboratório de Transformação Mecânica (LdTM), Depto. Engenharia, UFRGS, RS, Brasil; denis.villarinho@ufrgs.br.

7 Eng. de Minas, Metalúrgica e Materiais, Dr., Coordenadora. Lapec, Depto. Engenharia, UFRGS, RS, Brasil; celia.malfatti@ufrgs.br. 


\section{INTRODUÇÃO}

A liga NiTi, conhecida como nitinol, tem conseguido grande destaque para aplicação biomédica devido às suas propriedades mecânicas de superelasticidade e memória de forma. Porém estudos comparativos de biocompatibilidade entre ligas ${ }^{(1)}$ mostram que o íon níquel solubilizado pode apresentar uma série de reações adversas, embora ainda seja fato controverso, pois estudos reportam que a liga não apresenta citotoxicidade. ${ }^{(2,3)}$. Buscando eliminar a presença de níquel na superfície, tratamentos superficiais têm sido propostos com o objetivo de modificar a composição química e permitir uma maior biocompatibilidade para o nitinol. O emprego de tratamento de superfícies de implantes biomédicos é relativamente recente. Dentre os processos de tratamentos superficiais o processo de eletropolimento, por exemplo, tem sido desenvolvido visando à modificação da textura da superfície de titânio e suas ligas. ${ }^{(4)}$ A partir do processo de eletropolimento ${ }^{(5,6)}$ busca-se ao mesmo tempo realizar a modificação da morfologia superficial mantendo a estrutura de grão original. ${ }^{(7)}$ Os processos eletroquímicos de eletropolimento vêm sendo realizados principalmente em meio de fluoretos. Ainda que processos de eletropolimento empregando outros eletrólitos sejam estudados, ${ }^{(8-16)}$ eletrólitos à base de fluoretos têm permitido a obtenção de uma superfície nanoestruturada.

Respostas celulares como adesão, crescimento e diferenciação são afetadas pelas propriedades da superfície, como a composição, a rugosidade, a tensão superficial e a carga eletrostática do biomaterial [17]. A superfície do material pode influenciar na resposta biológica do paciente implantado, e dessa forma a sua caracterização é importante tanto nos protocolos de fabricação quanto na avaliação do desempenho dos biomateriais.

A integração de implantes ao tecido ósseo "in vivo" está fortemente relacionada com um aumento da rugosidade da superfície do implante. Osteoblastos humanos aderem melhor em superfícies rugosas do que em superfícieslisas e a adesão celular é geralmente aumentada em superfícies com rugosidade média (Ra) em torno de $1 \mu \mathrm{m}$ (17) $^{(17}$ topografia, contudo, tem duas escalas de importância: acima do tamanho da célula (microrugosidade) e abaixo do tamanho da célula (nanorugosidade). Quando a topografia está abaixo do seu tamanho, as células apreciam a superfície com menor rugosidade. Quando a topografia está acima do tamanho das células, uma rugosidade isotrópica formada por nanocavidades (bowllikenests), favorecea adesão. ${ }^{(18)}$ Diversos estudos ${ }^{(19,20)}$ mostram que quanto menor a rugosidade de uma superfície, maior é a tendência ao crescimento e à adesão celular. A rugosidade nanométrica é determinante nesse processo, não importando tanto a largura do sulco, e sim sua profundidade, ${ }^{(21)}$ e também e organização.

Este estudo tem por objetivo avaliar o efeito dos parâmetros operacionais do processo de eletropolimento sobre a morfologia e a composição da superfície de nitinol.

\section{MATERIAIS E MÉTODOS}

Para o desenvolvimento desse trabalho foram utilizadas amostras retangulares de NiTi medindo $32 \times 4 \mathrm{~mm}$, isolando-se uma área de $0,8 \mathrm{~mm}^{2}$. As amostras foram lixadas manualmente com lixas de carbeto de silício grana 120 até 2.500 , sabão neutro e água; com posterior polimento em pasta de diamante. Para o eletropolimento, foi 
utilizada uma fonte geradora (MPC-303DI, Minipa), e solução ácida à base de ácido fluorídrico (ácido sulfúrico 60\%, glicerina 30\% e ácido fluorídrico 10\%)a temperatura de $25^{\circ} \mathrm{C}$, com cátodos de platina e agitação por 4 minutos. A Tabela 1 apresenta e descreve as amostras analisadas no presente estudo.

Tabela 1. Descrição das amostras em estudo

\begin{tabular}{c|l}
\hline Amostra & \multicolumn{1}{|c}{ Descrição do tratamento superficial } \\
\hline Como recebida & Sem tratamento superficial. \\
\hline Lixada & Lixada até grana 2000. \\
\hline ET1 & $\begin{array}{l}\text { Lixada até grana 2000; Parâmetros do eletropolimento: } 0,100 \\
\text { A/cm }{ }^{2} \text { 4 minutos. }\end{array}$ \\
\hline ET2 & $\begin{array}{l}\text { Lixada até grana 2000; Parâmetros do eletropolimento: } 0,125 \\
\text { A/cm }{ }^{2} \text { 4 minutos. }\end{array}$ \\
\hline ET3 & $\begin{array}{l}\text { Lixada até grana 2000; Parâmetros do eletropolimento: } 0,250 \\
\mathrm{~A} / \mathrm{cm}^{2} ; 4 \text { minutos. }\end{array}$ \\
\hline
\end{tabular}

A topografia das amostras foi verificada por AFM (Microscopia de Força Atômica) através de microscópio da marca SHIMADZU, modelo SPM - 9500J3, ondeobtevese os parâmetros de rugosidade média $(\mathrm{Ra})$, rugosidade média quadrática $(\mathrm{Rms})$ e rugosidade máxima (Ry) A composição química da superfície foi determinada pela técnica de RBS (Rutherford BackscatteringSpectroscopy). Para os ensaios de RBS foi utilizado um acelerador Tandem de $3 \mathrm{MV}$, com feixe de $\mathrm{He}^{+}$de $2 \mathrm{MeV}$. Em todas as amostras, a incidência do feixe foi perpendicular à superfície, com ângulo de detecção de $165^{\circ}$.

\section{RESULTADOS}

As Figuras 1 e 2 mostram as imagens obtidas por AFM das superfícies das amostras de nitinol, Como Recebida, Lixada e após processo de eletropolimento com variação dos parâmetros operacionais.
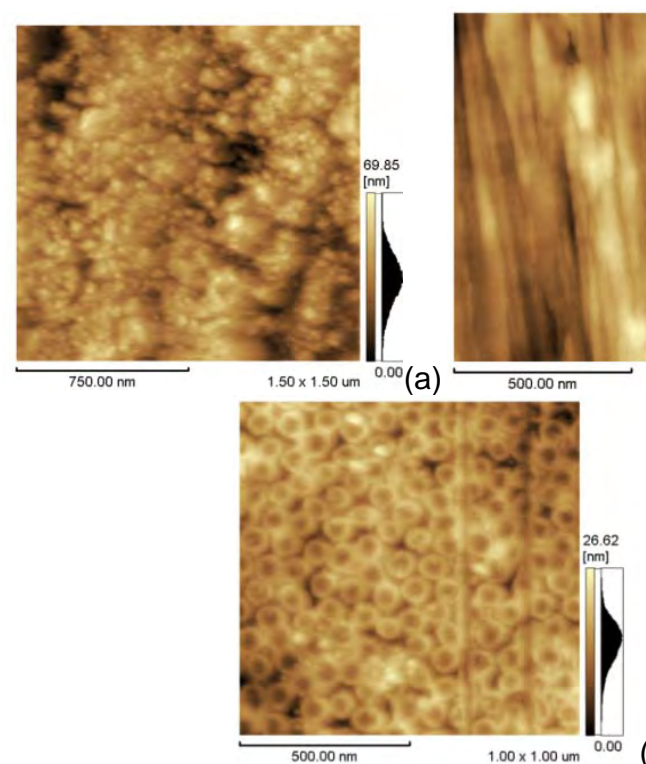

(d)
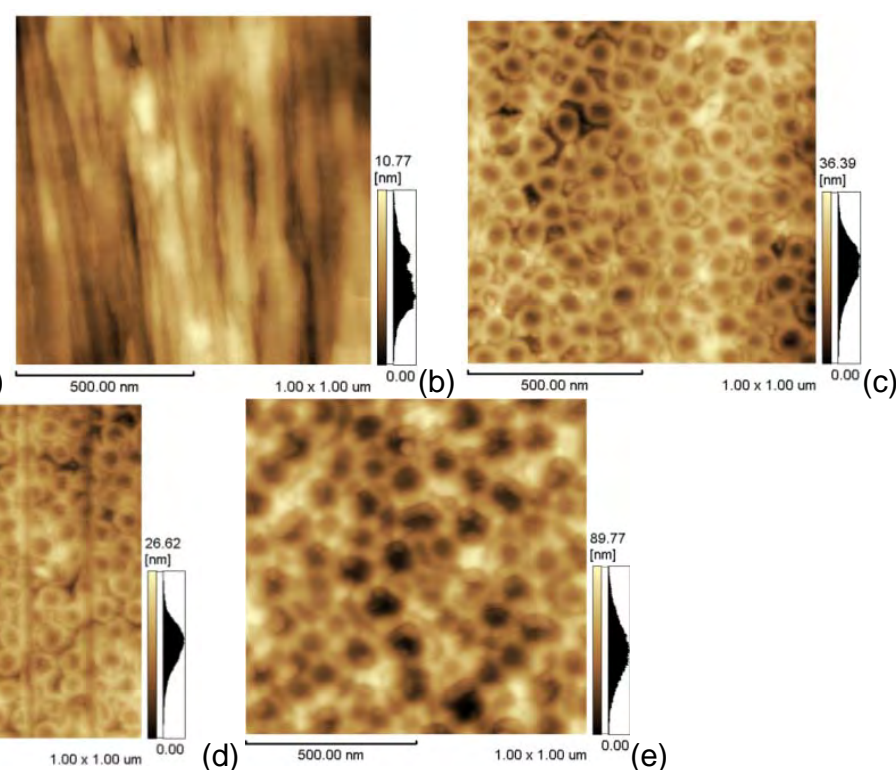

(a) Como Recebida; (b)

Figura 1. Imagens de topo das
Lixada; (c) ET1; (d) ET2; (e) ET3. 


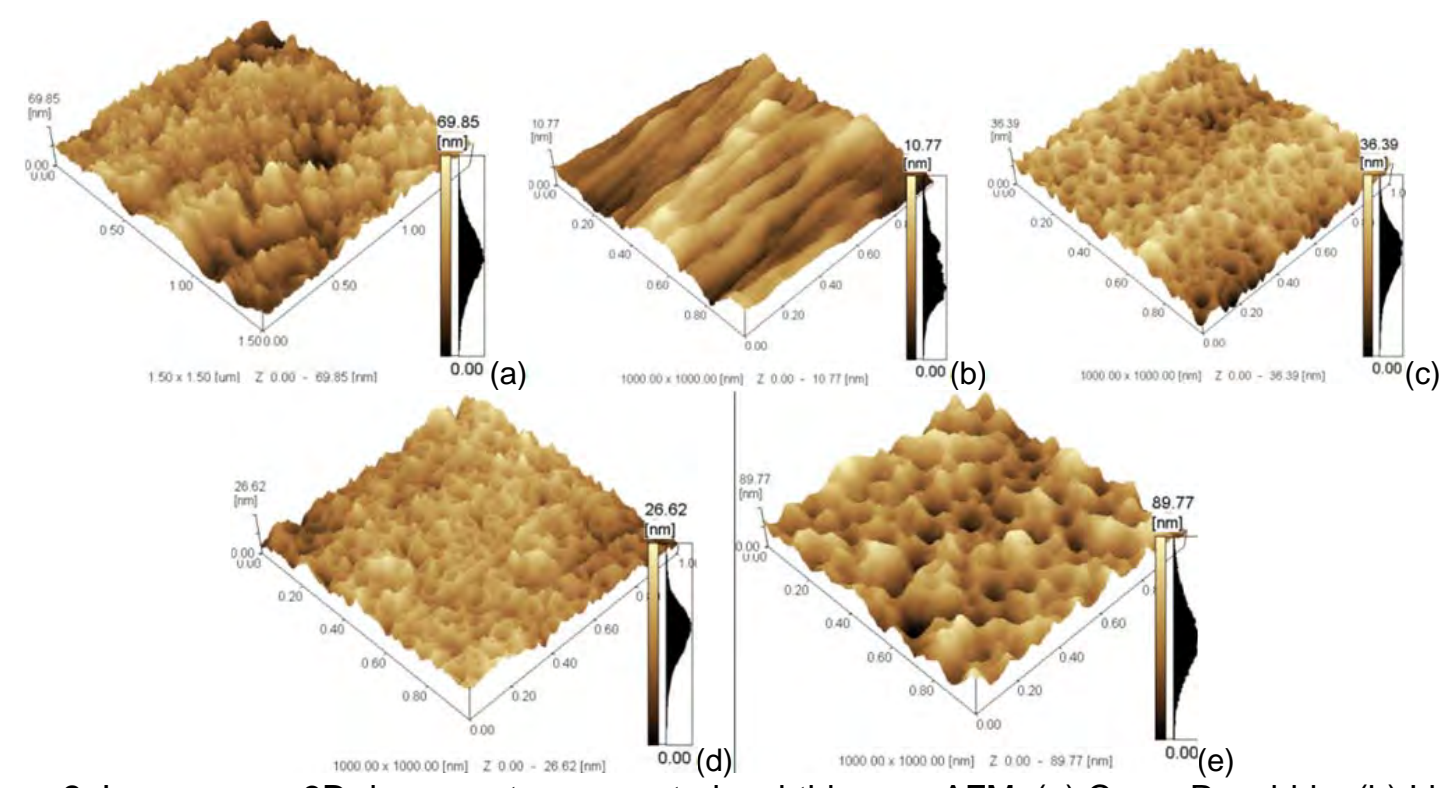

Figura 2. Imagens em 3D das amostras em estudo, obtidas por AFM. (a) Como Recebida; (b) Lixada; (c) ET1; (d) ET2; (e) ET3.

A partir da análise por AFM foi possível avaliar a rugosidade superficial em escala nanométrica (Tabela 2), bem como o tamanho das nanoestruturas formadas nas amostras ET1, ET2 e ET3 (Tabela 3)

Tabela 2. Rugosidade média nanométrica das amostras em estudo

\begin{tabular}{ccccc}
\hline Amostra & $\begin{array}{c}\text { Densidade de } \\
\text { corrente }\left(\mathrm{A} / \mathrm{cm}^{2}\right)\end{array}$ & $\mathrm{Ra}(\mathrm{nm})$ & $\mathrm{Rms}(\mathrm{nm})$ & $\mathrm{Ry}(\mathrm{nm})$ \\
\hline ET1 & 0,100 & 7,0 & 8,5 & 26,6 \\
ET2 & 0,125 & 2,7 & 3,4 & 13,0 \\
ET3 & 0,250 & 11,9 & 14,9 & 44,4 \\
Lixada & Não se aplica & 1,4 & 1,7 & 5,3 \\
Como recebida & Não se aplica & 7,9 & 9,9 & 33,9 \\
\hline
\end{tabular}

Tabela 3. Diâmetro médio das nanoestruturas obtidas por eletropolimento

\begin{tabular}{c|c}
\hline Amostra & Diâmetro das nanoestruturas $(\mathrm{nm})$ \\
\hline ET1 & $55 \pm 10$ \\
\hline ET2 & $39 \pm 4$ \\
\hline ET3 & $71 \pm 15$ \\
\hline
\end{tabular}

A Figura 3 apresenta os resultados de RBS das amostras Como Recebida e Eletropolidas. Todas as amostras eletropolidas apresentaram o mesmo comportamento, e um perfil de curva muito semelhante e por isso foram representadas em uma única curva. 


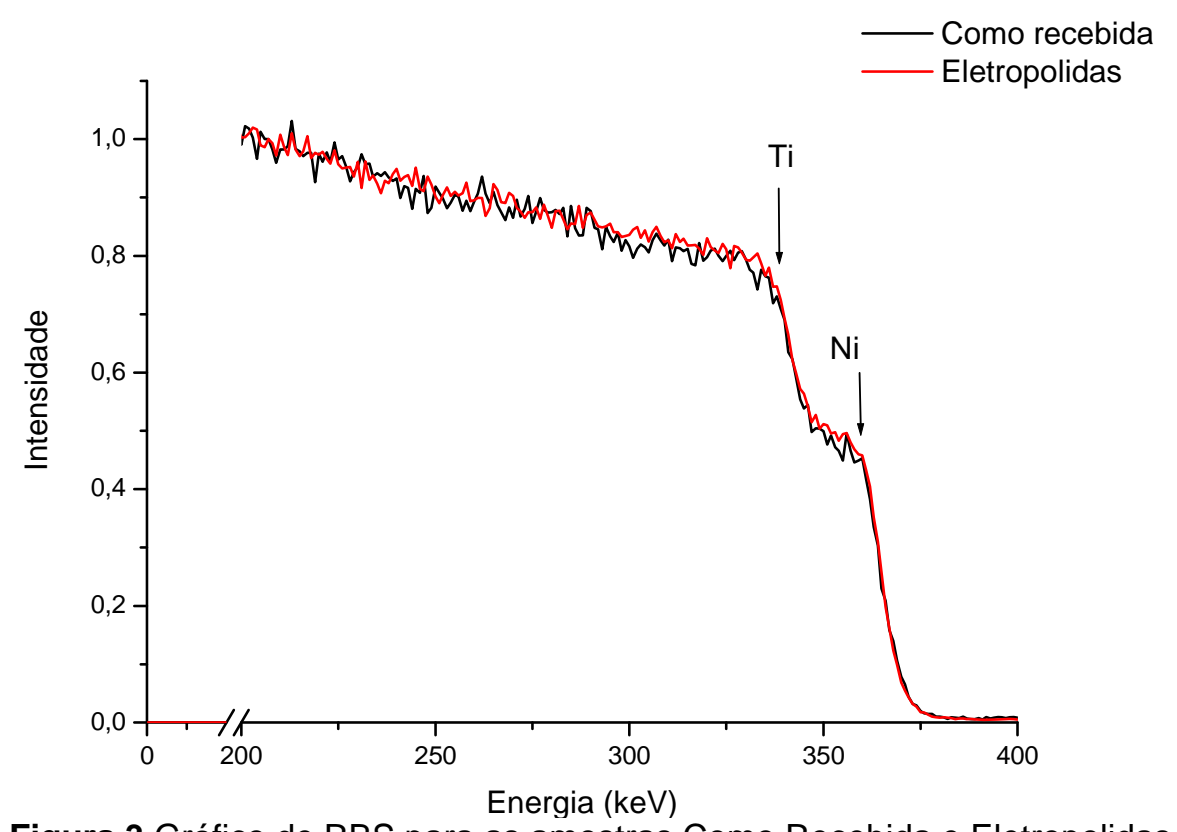

Figura 3.Gráfico de RBS para as amostras Como Recebida e Eletropolidas.

\section{DISCUSSÃO}

As imagens das Figuras 1 e 2 mostram que o eletropolimento promoveu alterações de morfologia na superfície das amostras, provocando a formação de nanocavidades. Essas nanocavidades aparecem bem definidas nas amostras ET1 e ET2 (Figuras 1c e 1d), onde a densidade de corrente utilizada foi menor. Já na amostra ET3, cuja densidade de corrente utilizada foi próxima ao dobro da usada nas amostras anteriores (Tabela 1), as nanocavidades já apresentam-se menos definidas, porém maiores. Isso mostraque entre a formação das nanocavidades prevaleceu a formação de regiões de óxido, evidenciada pelas áreas escuras na Figura 2e. A formação dessas nanocavidades está relacionada com o processo de dissolução anódica, conforme já mostrado por outros autores. ${ }^{(22)}$ Os resultados da Tabela 2 mostram também que quanto menor a densidade de corrente utilizada, menor a rugosidade superficial obtida, comparando-se com a rugosidade da amostra Lixada. Embora a rugosidade da amostra Como Recebida apresente-se próxima à amostra ET1 e abaixo da amostra ET3, a morfologia da amostra Como Recebida não apresenta a organização nanométrica. Como foi mencionado anteriormente, as células aderem menos a superfícies de titânio com irregularidades de dimensão maior que o tamanho da própria célula, devido a sua inabilidade de estabelecer área de contato suficiente com o substrato. ${ }^{(23)}$ Contudo, estudos mostraram que 0 aumento da rugosidade em escala nanométrica e micrométrica (mas abaixo do tamanho da célula) podem promover uma melhor osseointegração em implantes com titânio, ${ }^{(24)}$ influenciando na diferenciação dos osteoblastos, proliferação e produção da matriz sobre a superfície metálica. ${ }^{(25)}$

Fazendo uma relação entre as amostras ET1 e ET3, observa-se que não houve significativa diferença entre os valores do diâmetro médio das nanoestruturas, indicando que essa característica não é influenciada, de forma importante, pelo aumento da densidade de corrente. Ainda nesse contexto, observa-se que densidades de correntes maioresaumentam a profundidade das nanoestruturas, evidenciadas pelos valores de Ry (Tabela 3). Segundo alguns autores, ${ }^{(21)}$ a profundidade do sulco nanométrico é relevante no processo de adesão celular e favorece o processo de osseointegração. 
Estudos $^{(19,20)}$ mostram que quanto menor a rugosidade de uma superfície, maior é a tendência ao crescimento e à adesão celular. As amostras ET1 e ET2 apresentaram uma rugosidade média ( $\mathrm{Ra}$ ) menor quando comparadas com a ET3 (Tabela 2), mostrando-se mais adequadas ao crescimento celular.

Conforme Figura 3, o gráfico obtido por análise de RBS para a amostra Como Recebida apresenta pontos respectivos da presença de titânio e níquel na superfície da liga, conforme o esperado; resultados semelhantes foram encontrados por outros estudos. $^{(26,27)}$ Observa-se que o resultado de RBS para as amostras eletropolidas apresentam picos correspondentes ao titânio e ao níquel, conforme está indicado na Figura 3, sendo a curva bastante semelhante à curva da amostra Como Recebida. Esse resultado evidencia que o tratamento superficial de eletropolimento não modifica a composição superficial.Como é conhecido, no processo de eletropolimento há somente a remoção de material da superfície da amostra através da liberação de íons de $\mathrm{Ni}$ e Ti, e os resultados de RBS (Figura 3) evidenciam que não houve dissolução preferencial de um elemento deixando a superfície enriquecida do outro. Durante o processo de eletropolimento não há também a formação de uma camada passiva que possa reduzir o processo de liberação de íons da camada superficial. Pois durante o eletropolimento o processo de dissolução predomina em relação ao processo de formação de um óxido (camada passiva). Nesse sentido, trabalhos estão sendo desenvolvidos com 0 objetivo do emprego de um processo de tratamento superficial que favoreça a formação de uma camada passiva e estável eliminando a liberação de íons de Ni.

\section{CONCLUSÃo}

Os resultados deste estudo mostraram que o eletropolimento de nitinolcom eletrólito a base de fluoreto proporciona uma nanotexturização da superfície, através da obtenção de estruturas na forma de nanocavidades. Contudo, essa modificação na topografia não elimina o níquel da superfície.

\section{Agradecimentos}

O presente trabalho foi realizado com o apoio da Capes, entidade do Governo Brasileiro voltada para a formação de recursos humanos. Os autores agradecem também o apoio financeiro do CNPq e da Fapergs.

\section{REFERÊNCIAS}

1 McMAHON, R. et al. A comparative study of the cytotoxicity and corrosion resistance of nickel-titanium and titanium-niobium shape memory alloys.ActaBiomateriallia, v. 8, p.2863-2870, 2012.

2 DINCA, V. C. et al. Nickel-titanium alloy: Cytotoxicity evaluation on microorganism culture.Applied Surface Science, v. 252, p. 4619-4624, 2006.

3 WEVER. D. J. et al. Cytotoxic, allergic and genotoxic activity of a nickel-titanium alloy.Biomaterials, v. 18, p. 1115-1120, 1997.

4 CARVALHO, D. R. et al. Characterization and in vitrocytocompatibility of an acid-etchedtitanium surface.Braz. Dent. J., v. 21, n. 1, p. 3-11, 2010.

5 LAMOLLE, S. F. et al. Titanium implant surface modification by cathodic reduction in hydrofluoric acid: surface characterization and in vivo performance.Journal of Biomedical Materials Research A, n. 3, v. 88 A, pp. 581-588, 2008. 
6 XUANYONG, L. et al. Surface modification of titanium, titanium alloys, and related materials for biomedical applications. Materials Science and Engineering R, v. 47, p.49121, 2004.

7 NISHIGUCHI, S. et al.The effect of heat treatment on bone-bonging ability of alkalitreated titanium.Biomaterials, n. 5, v. 20, p. 491-500, 1999.

8 OCHOA-HERRERA, $V$. et al. Toxicity of fluoride to microorganisms in biological wastewater treatment systems. Water Research, v.43, p. $3177-3186,2009$.

9 CAMARGO, J. A. Fluoride toxicity to aquatic organisms: a review.Chemosphere, v. 50, p.251-264, 2003.

10 BARBIER, O. et al. Molecular mechanisms of fluoride toxicity.Chemico-Biological Interactions, v.188, p.319-333, 2010.

$11 \mathrm{CHU}, \mathrm{C} . \mathrm{L}$. et al. Effects of anodic oxidation in $\mathrm{H} 2 \mathrm{SO} 4$ electrolyte on the biocompatibility of NiTi shape memory alloy.Materials Letters, v. 62, p. 3512-3514, 2008.

12 YANG, C. et al. Anodization of the dental arch wires.Materials Chemistry and Physics,v.100 p.268-274, 2006.

13 CHENG, F.T. et al. Microstructural characterization of oxide film formed on NiTi by anodization in acetic acid. Journal of Alloys and Compounds, v.438, p. 238-242, 2007.

14 SZESZ,E. M. et al. Electrochemical and morphological analyses on the titanium surface modified by shot blasting and anodic oxidation processes. Thin Solid Films, v. 528, p.163-166, 2013.

15 MARINO,C. E.B.et al. Voltammetric stability of anodic films on the Ti6Al4V alloy in chloride medium.Electrochimica Acta, v. 5, p. 6580-6583, 2006.

16 MARINO, C. E. B. et al. XPS characterization of anodic titanium oxide films grown in phosphate buffer solutions. Thin Solid Films, v. 468, p.109- 112, 2004.

$17 \mathrm{ZHU}, \mathrm{X}$. et al. Effects of topography and composition of titanium surface oxides on osteoblast responses.Biomaterials, n. 18, v. 25, pp. 4087-4103, 2004.

18 BIGERELLE, M. et al. Improvement in the morphology of Ti-based surfaces: a new process to increase in vitro human osteoblast response.Biomaterials, n. 7, v. 23, p. 15631577, 2002

19 PONSONNET, L. et al. Relationship between surface properties (roughness, wettability) of titanium and titanium alloys and cell behavior.Material Science and Engineering $C$, v. 23, p. 551-560, 2003.

20 WIRTH C. et al. Nitinol Surface roughness modulates in vitro cell response: a comparison between fibroblasts and osteoblasts.Material Science and Engineering $C, \mathrm{v}$. 25, p. 51-60, 2005.

21 PONSONNET, L. et al. Effect of surface topography and chemistry on adhesion, orientation and growth of fibroblasts on nickel-titanium substrates.Materials Science and Engineering C, v. 21, p.157-165, 2002.

22 ZINGER, O. et al. Time-dependent morphology and adhesion of osteoblastic cells on titanium model surfaces featuring scale-resolved topography.Biomaterials, n. 14, v. 25, pp. 2695-2711, 2004.

23 COSTA, T. C. Avaliação da interface osso-implante em superfícies de $\mathrm{Ti}_{6} \mathrm{Al}_{4} \mathrm{~V}$ e do $\mathrm{Aço}$ ISO 5832-9 tratadas eletroquimicamente.2012. 103 f. Dissertação (Mestrado) - Curso de Programa de Pós-graduação em Engenharia e Ciências Dos Materiais - Pipe, Universidade Federal do Paraná, Curitiba, 2012.

24 RUPP, F. et al. Roughness induced dynamic changes of wettability of acid etched titanium implant modifications. Biomaterials, v. 25, n. 7, pp. 1429-1438, 2004.

$25 \mathrm{KIESWETTER,} \mathrm{K}$. et al. Surface roughness modulates the local production of growth factors and cytokines by osteoblast-like MG-63 cells. Journal of Biomedical Materials Research, n. 1, v. 32, pp. 55-63, 1996.

26 LEVINTANT-ZAYONTS, N. et al. Surface characterization and wear behavior of ion implanted NiTi shape memory alloy.Vacuum, v. 83, p. S220-S223, 2003.

27 GOLDBERG, F. et al. NiTi thin film characterization by Rutherford backscattering spectrometry.MaterialsScience and Engineering B, v. 40, p. 185-189, 1996. 